\title{
Shoestring Social Media: Building a Social Media Presence for UNCG's Special Collections and University Archives
}

$\mathrm{I}$ n his 1990 article "Preoccupied with our own gardens': Outreach and Archivists," Timothy L. Ericson identifies a number of issues impeding the adoption of critically important outreach programming in archives, many of which ring true regardless of the method or mode of outreach. Ericson argues that outreach "should be ongoing, not simply a series of haphazard short-term projects." The work "should be tied to our mission statement" and "have short-term and long-term goals, just like acquisitions development." 'Outreach should be considered a vital component of all archival practice.

Ericson wraps up his article with a call for action, stating that "it is time for us to do something rather than simply continue to talk about it." ${ }^{2}$ Carefully planned outreach, regardless of the methods employed, is critical to the development of archives. Ericson further argues that "if people do not know what archivists are, or what they do, it is simply because archivists have not touched their lives in any meaningful way - in much the same way as many do not know what a podiatrist is until they have problems with their feet." 3

In today's world, social media is a part of everyday life for the majority of adults across the United States. A 2015 survey by the Pew Research Center showed that $65 \%$ of all adults in the United States use at least one social networking site. ${ }^{4}$ Adoption rates have either remained steady or grown across gender, income, education, regional, and race/ethnicity demographics over the last ten years. While many of the individual social network platforms have shifted in popularity over the last decade, the general interest in social media and social sharing remains high.

With such high adoption rates, archives and special collections cannot afford to ignore this important venue for outreach and awareness building. But building a social media presence, particularly one that crosses multiple platforms, can seem intimidating. Not only must one be familiar with the platforms themselves, but one also must be clear on the amount of time that can be devoted to social media as well as on the targeted audience for the communications. An active social media presence requires more than just creating a page. "If you build it, they will come" is not an effective strategy for developing social media presence. New content must be frequently posted, and accounts must be monitored to fulfill the goal of social media as a platform for education and engagement.

Developing a social media presence, however, need not be intimidating or all-consuming. With careful planning, collaboration, and reflection, any archives or special collections can establish and develop an active social media platform. Engagement through social media can readily align with the outreach objectives outlined by Ericson and become sustained communications methods that are aligned with institutional goals. In this case study, we will explore how staff of the Martha Blakeney Hodges Special Collections and
University Archives (SCUA) at the University of North Carolina at Greensboro (UNCG) established and built a social media presence that stretches across multiple platforms and audiences to spread the word about their collections and their work. We will also examine the issue of sustainability planning and assessment for continued growth and development of a social media presence.

\section{Starting Small:}

\section{The Spartan Stories Blog}

On October 1, 2012, Spartan Stories, a blog designed to share tales from the long history of the university, was launched. ${ }^{5}$ This platform aimed to promote University Archives and University history through the public dissemination of short (500-700 words plus photographs) blog posts about specific people, events, places, etc. in UNCG history. Each Monday morning, a story would be posted.

Spartan Stories drew contributions from numerous staff members in Special Collections and University Archives (SCUA). In its first year, eight of the ten full-time employees in SCUA contributed at least one post. Contributions included blog posts from the Manuscripts Curator and the Curator of the Women Veterans Historical Project, both of whom drew from their collections to tell stories of individuals with strong ties to UNCG's past. Additionally, two undergraduate student interns from the History Departmentone in Fall semester and one in Spring semester-added blog posts related to their primary research topics. 
With multiple contributors, a shared spreadsheet was created to track who would be responsible for posts on given days and what the primary topic of the post would be. Staff members were allowed to sign up for as many or as few posts as they felt comfortable contributing, and they were encouraged to write on topics of personal interest or on topics in which they had already conducted research (for exhibits, classroom presentations, reference queries, etc.). By encouraging the reuse of existing research, the individual blog post creation process was less time consuming, and blog post writers felt more comfortable signing up to contribute multiple posts.

At the conclusion of the 2012-2013 academic year, we assessed the success of Spartan Stories in meeting its key goals of broadly communicating University history across campus and to the broader community of UNCG supporters through the use of Google Analytics. The analytics showed that, during its initial eight months, Spartan Stories received 1,714 visits $(3,061$ page views) from 1,171 unique visitors. Nine-hundred sixty-six visits came from readers using UNCG's internet service $(56.4 \%)$. While this indicated a high readership from faculty, staff, and students, it also meant that $43.6 \%$ (748) of the total visits came from outside of the UNCG campus.

Additionally, the analytics demonstrated that readership steadily increased from October through April (with a slight - but expected - drop off in May and June due to summer break). Large spikes in readership occurred when specific stories were shared through the University's primary social media outlets (the official UNCG Facebook and Twitter feeds).

\section{Building from Spartan Stories}

With the success of Spartan Stories, we sought additional venues for promoting University history, specifically social media venues. While Spartan Stories was created with the hope of building a broad audience on campus and off, we wanted to focus our initial foray into social media on a platform that would allow us to reach the student population. We also wanted a platform that could be integrated easily within the University's existing social media framework.

\section{Twitter}

Twitter was identified as the ideal platform to grow our social media presence. According to the Pew Research Center survey on social media usage, in 2015, approximately $23 \%$ of all online adults reported using Twitter. But, in the 18-29-year-old age range that we specifically hoped to reach, the use jumped to $32 \% .^{6}$ Additionally, UNCG had an active institutional Twitter presence, as did many of the departments on campus that worked primarily with students (Student Affairs, Undergraduate Admissions, etc.). Sharing our content on Twitter allowed us to be integrated into this broader web of communications with students across campus.

We did not settle on Twitter without investigating other options. Instagram and Facebook were also considered as initial launch points. Instagram, while extremely popular among our targeted audience, proved problematic at the time. The University did not yet have an official presence on Instagram, so the pre-built audience would not be in place to share our content. Additionally, Instagram did not offer a desktop application, meaning that any photographs posted would need to be posted to the site through a mobile device. As we were working with a large cache of digitized images already stored on a local drive, at the time, this would have required staff to email the images to themselves, access the email on a mobile device, and then post from that mobile device to Instagram. Between this labor-intensive workflow and the lack of an existing UNCG network, Instagram was ruled out as a possibility for our initial platform.

Initially, we chose not to join Facebook because a dormant Facebook Group dedicated to SCUA existed. We knew that we would need to convert the group to a fan page in order to meet Facebook's terms of service for an account of a non-person. Additionally, while the University had an active presence on Facebook, many of the student-oriented offices and departments did not. Or, if they had a presence, it was not as active as their Twitter account.

We claimed the Twitter username "UNCGArchives" in January 2014, but consistent use of the account did not begin until March. March was specifically chosen as the launch date because of its designation as Women's History Month. As a school that was founded as a woman's college (and remained a woman's college until the first male undergraduates arrived in Fall 1964), UNCG's University Archives as well as the other collections within SCUA stand as rich resources related to women's history. Launching our Twitter presence during this month allowed us to draw on our existing content bank and participate in a wellknown and well-used social media theme.

\section{Tumblr}

Shortly after launching our Twitter account, in July 2014, we established a presence on Tumblr. Again, Tumblr was purposefully selected because of its younger demographic. Forty-six percent of Tumblr users in 2013 were between 16 and 24 years old; 28\% between 25 and 34. Additionally, the Tumblr platform has unique attributes that make it an excellent tool for 
outreach in special collections and archives. The reblogging feature allows for sharing another person's post with one's readers, add additional comments to the post, and maintain the provenance of the original information. Readers will still be able to clearly see who posted the information, no matter how many times it is reblogged. Additionally, Tumblr users tend to spend more minutes per visit on the site than on other social media sites. Tumblr CEO David Karp noted in 2014 that, on average, Tumblr users spend 14 minutes per visit on the site, "about a minute and a half higher than a Facebook visit, a few minutes higher than an average Twitter visit." ${ }^{8}$ Special collections and archives can share more detailed content (with links to even more information) and feel confident that, within the Tumblr platform, the information will remain properly attributed to the creating account.

Unlike Twitter, Tumblr proved a bit of a challenge regarding initial promotion as the University itself did not have a presence on the platform. Because we could not rely on others within the institution to help us grow our audience, we took a two-pronged approach to promotion. First, we followed a number of other archives and special collections accounts, allowing us to learn from their posts how best to share information on Tumblr. Following these similar accounts also promoted our presence so they could help share our posts. Second, we used our existing Twitter account to publicize the Tumblr. Many students have active accounts on both sites and were willing to like our page and share our content on Tumblr as well as Twitter. While we saw growth through these two approaches, our audience grew exponentially when we were featured as a "Trending Blog" by Tumblr in March 2015.

\section{Facebook}

With our Tumblr firmly established, we decided to revisit the idea of a Facebook page. We recognized Facebook, with its widespread adoption across almost all demographics, as a necessary component of a vital social media program. With $62 \%$ of all U.S. adults using Facebook, it was not a platform that we could afford to avoid.?

After deleting the dormant Facebook Group, a Facebook Page was established. While we wanted to expand our presence, we knew that we did not want to stretch ourselves too thin with posts across many platforms. We found a free web-based service called "If This Then That" (http://www.ifttt.com) that allows a user to create "recipes" that will automatically push content from one social media platform to another, using particular triggers to produce particular actions. For example, if a Tumblr text post is made, then a link to that post is automatically posted to the associated Facebook Page. If a Tumblr photo post is made, then the photo is reproduced on the Facebook Page along with any accompanying text provided.

After a month of testing with the Facebook Page set to private, we went public with this automatically-populated Facebook presence in April 2015. As expected, most of the shares and new likes come from UNCG alumni and the UNCG Alumni Association.

\section{Planning and Implementation}

Our social media presence was purposefully developed in stages. With each stage of growth, we expanded our range of content and included more staff members and student workers. Expanding in this strategic way allowed us to gauge time requirements, demonstrate platforms to staff members who were unfamiliar with them, and learn more about what content works best on which platform.
In developing our social media presence, we followed a serious of steps that contributed to the successful growth of our platforms. Diving into social media without a plan for development and growth is a recipe for disaster (and abandoned accounts!). We began the process by developing a social media communications plan to guide our decision making and our content creation. We followed with the construction of a content calendar. We also tapped into existing communications channels to spread our reach and gain new followers. And we regularly assessed our platforms to learn more about what works well - or what might not work at all.

\section{Communications Plan}

Our communications plan started with a review of existing social media documentation across the University. UNCG's University Communications department created a "Social Media Standards" site which provides best practices and guidance for proper use of an account officially representing a University entity. ${ }^{10}$ These guidelines provide advice on voice, expectations of responsiveness, legal issues, etc. Reviewing these guidelines prior to starting a social media presence (and having staff members review the guidelines before contributing to our social media presences) allows consistency across our platforms as well as conformity with the University's expectations for social media accounts.

Within SCUA, we also created a list of questions to guide our decisionmaking process:

- Who are we trying to reach? If there are multiple audiences, who is the primary audience (most important to us in this effort)?

- What types of content do we wish to share? Are we looking for a platform that is photo-centric or more text heavy? 
- How much time do we have to devote to this platform, both creating content and monitoring and moderating conversations?

- What footprint does UNCG currently have on this platform? What departments or offices are using it?

When considering adoption of a new platform, these basic questions allowed us to determine whether the platform was right for our needs and whether we would be able to incorporate it effectively into our daily work.

We also sought consistency in branding across platforms. Therefore, as soon as a new platform was being considered, we reserved the username "UNCGArchives" and set the account to "private." Doing so allowed us to ensure we would have the same username across all of our social media outlets. If a platform was not deemed appropriate for our needs at the time, we simply kept the account private and maintained the user name, with the knowledge that a platform that did not meet our needs today may be perfect in the future. When a platform was

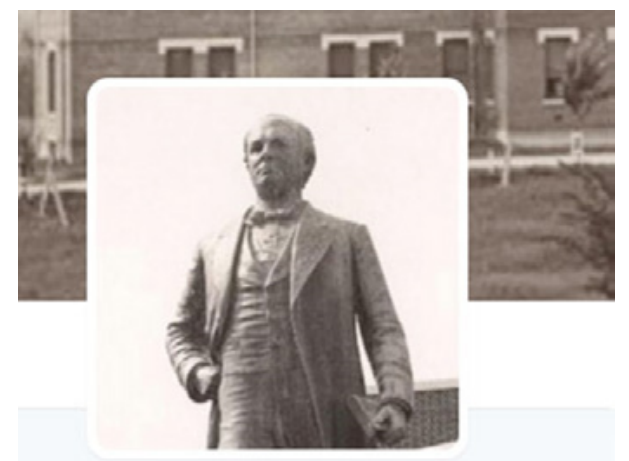

$$
\begin{aligned}
& \text { UNCG Archives } \\
& \text { @UNCGArchives } \\
& \text { Photos and other fun stuff from UNCG's } \\
& \text { Special Collections \& University Archives! } \\
& \text { We're also on Tumblr, IG \& FB } \\
& \text { (UNCGArchives) } \\
& \text { Greensboro, North Carolina } \\
& \text { \& library.uncg.edu/info/depts/scu... } \\
& \text { 面 Joined November } 2013
\end{aligned}
$$

Figure 1: Profile for UNCGArchives on Twitter public, we also utilized the same profile photograph for each platform for visual continuity and branding consistency. A shared spreadsheet listing accounts created allowed us to easily track where we had already created this kind of footprint, even if the account was dormant and hidden from public view.

\section{Content Calendar and Content Bank}

With the selection of a new platform, we developed a content calendar. This calendar detailed our posting schedule as well as outlined which staff member was responsible for posting in which time blocks. This content calendar is reviewed at the end of each semester to determine what changes may be needed based upon assessment. It is also frequently reassessed on a semiannual basis in order to adjust content to match audience interest and engagement or to highlight areas of focus.

The content calendar was based on our collection strengths as well as some commonly-used social media themes. For instance, posts on Thursday were part of "Throwback Thursday" (or "TBT"), a popular theme used across most of the social media platforms to share photographs or other content from previous years. As an archival repository, of course, the bulk of our posts could fall into the "Throwback adopted and the account was made

Thursday" category. But we specifically scheduled Thursday posts to use the "Throwback Thursday" hashtag and share our content in this way across platforms in order to reach a broader audience and encourage sharing of our content within this common theme.

On the other hand, we also developed our own theme days to reflect collection strengths. Each Wednesday afternoon, we currently post a cover or other content from our Robbie Emily Dunn Collection of American Detective Fiction. This collection features detective novels written by women authors as well as novels featuring female detectives. As a way of thematically grouping these, we coined "Whodunit Wednesday" and incorporated this into our content calendar. Ideally, the content and the themes we develop and use reflect our key "passion points" - the topics that bridge our strengths with our audience's interests.

We also seek to repurpose existing content and grow a bank of reusable content. For example, items scanned for use in exhibits, classroom instruction, or reproduction requests from patrons are filed into our content bank for future use on social media. Similarly, cell phone cameras are used to quickly snap a photograph of a rare book before returning it to the shelf or of an interesting item found while processing an archival collection.

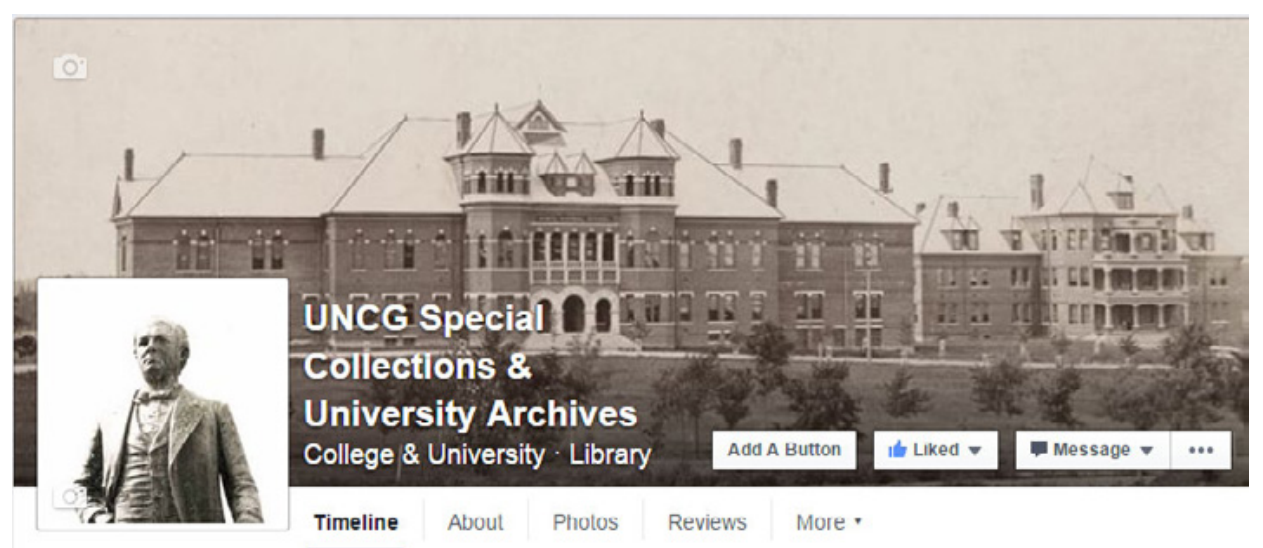

Figure 2: Profile for UNCGArchives on Facebook 
Digitized images stored in our content management system can also be mined for social media sharing. This content is all placed on a shared drive that is accessible to all of the people in our department.

Additionally, we seek to promote more than just the content of collections in our social media work. We also want to focus on the people and processes that are critical to preserving and making available the interesting pieces we share, allowing us to educate users and hopefully build a team of advocates who understand the importance of the behind-the-scenes work being done in our archives. A "Staff Picks" series in 2015, for example, consisted of a weekly post across our social media platforms featuring one staff member who chose an item from the collection to highlight. These posts allowed us to showcase underused collections while also emphasizing the work of the people who produce our social media content enjoyed by the audience every day.

\section{Growth through Existing Communications Channels}

When launching a presence on a new social media platform, our first step is to contact the person who manages the University's primary social media feeds to let her know of our account and explain (in broad terms) a sense of the type of content we will be sharing through this account. At UNCG, the University Communications department manages the social media content representing the University as a whole. These are the campus social media presences that typically have the most followers. They are also the accounts that most commonly reach across the various demographics we aim to reach on different platforms: faculty and staff, students, and alumni.

With the primary University account manager informed, we also were sure to inform managers of other campus accounts that might help us reach our targeted audience. For instance, UNCG's Alumni Association has a strong following on Facebook. Notifying them of our account allowed them to easily share our content with a large number of followers. In turn, we can gain followers from that sharing. Similarly, campus accounts that primarily target incoming or current students, such as the Admissions Office or Student Affairs, were quickly notified of our Twitter account. Their retweets often lead to an increase in followers.

We also reciprocate by sharing their content that is relevant to SCUA or University history. Often, when an event or activity is occurring, we can share the post of another campus office and provide a brief amount of historical context. For example, each summer the Office of New Student and Spartan Family Programs within the Division of Student Affairs hosts SOAR (Spartan Orientation, Advising, and Registration) for new undergraduate students. On Twitter, they designate a specific hashtag for the SOAR event and actively encourage all SOAR participants to post throughout their orientation session. We are able to add historical perspective to many of their posts through historic campus photos and "fun facts" that introduce these new UNCG students to campus history and to University Archives.

In addition to growth through established campus communication channels, we include a mention of our social media outlets in each instruction session offered, particularly instruction sessions focused on our major social media themes (such as University history). The mention can be as simple as including social media accounts on a slide in a PowerPoint presentation. When the occasion warrants, however, we will also provide a detailed outline of our content calendar or an explanation of how students might use social media as a way of contacting us with questions or reference requests.

We also created promotional postcards that are used in a variety of settings to spread the word of our social media accounts. These postcards feature photographs from University Archives on the front with a list of all of our social media accounts (as well as a link to our digitized collections and our departmental reference email address) on the back. During instruction sessions, during events in the library, and during non-library events like Alumni Reunion Weekend, we distribute these postcards to students, faculty, staff, and alumni. They are also included in the University Libraries' information packets for donors. And they are available in our SCUA reading room any time we are open.

\section{Assessment}

When the Spartan Stories blog was created in October 2012, we linked it to a Google Analytics account to track the impact of the site. Every six months, a brief report is created to document the site's readership. In this report, we include the number of page views, the number of unique visitors, the number of readers from within North Carolina, the number of viewers coming to the site from UNCG campus IP address, and the way in which the reader reached our site (direct link, Facebook, Twitter, Tumblr, etc.). All of these measures are provided in Google Analytics and, combined, they allow us to see, to some degree, who we are reaching, and how they are finding us.

In the first year of the Spartan Stories blog, we uncovered some somewhat surprising information that helped us better target our future social media efforts. Because the blog was new, we anticipated that the primary readership would be faculty and staff 
on our campus. We found that, from October 2012 to September 2013, 1,547 visits came from readers accessing the site on the UNCG campus or through a UNCG proxy (50.99\%). While this does indicate a high readership from faculty, staff, and current students, it also means that $49.01 \%$ $(1,487)$ of the total visits came from outside of the UNCG campus. In digging further into Google Analytics, we found that links shared by others

Facebook also has an analytics platform built into its Pages system. This platform, known as Insights, is accessible to account holders from the SCUA Facebook Page. In Facebook, we make a monthly report of the total number of likes for the page, the total number of new likes for the page, and the total number of engagements (including individual post likes, comments, and shares, as well as clicks on links embedded within posts).

\section{$\mathbf{6}_{\text {When staff members can see clearly that their }}$ contributions are being recognized and shared across social media, they are more likely to see their contributions as important to the overall cause of promoting the department...99}

through their social media accounts (this being prior to our accounts) and search engine results drove a significant amount of traffic to Spartan Stories. And, when the readers found us, they tended to stay for a while. Once on the Spartan Stories site, users typically visited more than one page (averaging 1.75 pages per visit). The site saw a relatively low bounce rate $(76.80 \%)$ for a blog that focuses on individual stories, as opposed to an extended or interwoven experience.

With the launch of our Twitter, Tumblr, and Facebook accounts, we developed assessment techniques unique to each platform. Each site is distinctive in what it counts and what analytics it provides. We create an end-of-themonth assessment of each platform using the statistics tools built into the systems. For example, on Twitter, we report the total number of followers, total number of new followers, total number of retweets, and total number of favorites. This information is made available through Twitter's analytics site (http://analytics.twitter.com).
While Facebook and Twitter allow users to access data from across the fully active state of the account, Tumblr's analytics system is unique in that the user is only able to retrieve statistics for the past month. Making a monthly note of these statistics is critical in order to track growth, as Tumblr's analytics alone cannot provide information on use trends. On Tumblr, we track the total number of followers, the total number of new followers, and the total number of notes (which includes likes, comments, and reblogs).

On the first of each month, a report documenting these statistics is sent to each staff member who contributes to the social media efforts as well as to the department head. Sharing this information with all contributors is a vital part of building a social media team. When staff members can see clearly that their contributions are being recognized and shared across social media, they are more likely to see their contributions as important to the overall cause of promoting the department and the work that we do.
In addition to a focus on the statistics, however, the reactions we receive from UNCG students, faculty, and staff provide valuable feedback on our social media efforts. Be they comments on the social media platforms themselves or comments received when we are teaching classes or working with faculty, this "word of mouth" feedback helps refine platform use as well as content choices. When a post on a platform aimed at current students is shared or commented on by the students themselves, we know that the post was a success. We note the content of the successful posts and seek to emulate it in the future. For instance, tweets that included photographs from past commencements proved extremely popular with current students as well as UNCG faculty and staff on Twitter in 2014. Now, every semester, we share new commencement photos and facts on commencement day.

\section{Looking Forward}

With UNCG shifting much of its social media focus to Instagram, SCUA is looking to follow suit. In order to carry over our branding, we have reserved the UNCGArchives name on the network and established a profile using the same profile photograph shown on our other social media sites. Because Instagram does not allow for content to easily be pushed to the site from other platforms, we are currently investigating the best ways to incorporate this growing platform into our social media portfolio. Instagram also currently (as of June 7, 2016) does not have an integrated statistics module, but one is forthcoming. With this in place, we will be able to more strategically develop content and reach our audience in Instagram.

\section{Conclusion}

In today's world, social media simply cannot be ignored. It is a vital tool for 
modern communications, advocacy, and outreach. It is an essential resource if archives and special collections wish to reach and grow our audience and our audience's understanding of the valuable work that we do. Through a strategically-developed, team-based approach to building a social media presence, the UNCG Special Collections and University Archives integrated itself into conversations on social media networks. We are educating students outside of a classroom setting and reaching alumni and potential donors in a more casual environment.

In even the smallest archives, this step-by-step approach can be scaled to bring the repository into the social media sphere in an effective and sustainable way. By doing so, our audiences can find us in their everyday communications networks, and archivists can begin the process of initiating the meaningful engagements that Ericson promoted.

\section{References}

${ }^{1}$ Timothy L. Ericson, "Preoccupied with our own gardens': Outreach and Archivists," Archivaria 31

(Winter 1990-1991), 115.

${ }^{2}$ Ibid., 121.

${ }^{3}$ Ibid., 120.

${ }^{4}$ Perrin, Andrew. Social Media Usage: 2005-2015. Pew Research Center Internet Science Tech RSS. 2015. Accessed December 1, 2016. http://www.pewinternet. org/2015/10/08/social-networkingusage-2005-2015/.

${ }^{5}$ The Spartan Stories blog is accessible online at http://uncghistory. blogspot.com.

${ }^{6}$ Greenwood, Shannon. Twitter Demographics. Pew Research Center Internet Science Tech RSS. 2015. Accessed December 1, 2016. http:// www.pewinternet.org/2015/08/19/ mobile-messaging-and-social-media-2015/2015-08-19_social-mediaupdate_11/.

${ }^{7}$ What Brands Should Know about Tumblr Users - Infographic. The
Guardian. 2013. Accessed December 1, 2016. http://www.theguardian. $\mathrm{com} / \mathrm{media}$-network/media-networkblog/2013/jun/20/brands-knowtumblr-users-infographic.

${ }^{8}$ People Spend More Time on Tumblr than on Twitter or Facebook, CEO Brags. CNET. Accessed December 1, 2016. http://www.cnet. $\mathrm{com} /$ news/people-spend-more-timeon-tumblr-than-on-twitter-or-facebook-ceo-brags/.

${ }^{9}$ Duggan, Maeve. The Demographics of Social Media Users. Pew Research Center Internet Science Tech RSS. 2015. Accessed December 1, 2016. http://www.pewinternet. org/2015/08/19/the-demographicsof-social-media-users/.

${ }^{10}$ Social Media Standards Archives - UNCG BrandGuide. UNCG BrandGuide. Accessed December 1, 2016. http://ure.uncg.edu/ brandguide $/$ ?brandcat $=$ social - media standards.

\section{North Carolina Libraries}

Official Publication of the North Carolina Library Association

ISSN 0029-2540

All issues are available online free-of-charge at http://www.ncl.ecu.edu.

Back issues are available from the North Carolina Library Association office at 1811 Capital Blvd., Raleigh, NC 27604 , for $\$ 8$ an issue for those years prior to going online in 2002 , or $\$ 50$ for the annual print compilation beginning with Vol. 60 (2002). 